\title{
Research on equilibrium production in complex manufacturing process
}

\author{
Zhuang Yan \\ School of Economic and Management \\ Shengyang Aerospace University \\ Shengyang, China \\ Zhuangyan@sau.edu.cn
}

\begin{abstract}
As the economy continues to develop, changes in the market are becoming more diverse and personalized, and traditional single mode of production in large quantities has been unable to adapt to changing market needs. The mode of production within manufacturing is changing. Today, general product development cycle of China's manufacturing industry is longer; repeated utilization of product resources is low; utilization of manufacturing resources is poor; coordination between manufacturing planning and production control is insufficient. All the above problems result in long product manufacturing cycle, low quality rate and high manufacturing costs. Scientific and technological progress promotes the enterprise production management. More and more companies start to focus and adopt an equilibrium production method. Equilibrium production includes production line balance, scientific arrangement of production sequence and rhythm, rational distribution of production equipment, standardized processes, and supply of raw materials and punctuality of information access and so on. Finally, the equilibrium production may apply in the enterprise, to improve operational efficiency, reduce the accumulation of inventory, arrange process sequence of complex manufacturing reasonably, to reduce the operating time in a large degree.
\end{abstract}

Keywords-equilibrium production; production line balancing; mode of production

\section{INTRODUCTION}

Nowadays, rapid competition is more and more fierce with faster changes in market environment, and companies are facing pressures of lower cost, longer cycles and higher quality. In order to solve the above problem, embodiments of an equilibrium production become the key elements.

Equilibrium production was born in Toyota. Toyotastyle equilibrium production required the synchronous balance of product quantity and categories, which means while the total assembly gets parts from the former process every time, it should be uniform collection of various parts to achieve mix production. Avoiding collecting the same kind of parts in a certain period of time, results in uneven front steps, and thus consequently may lead to production disorder. Equilibrium production not only requires to complete the project, but also to complete their own production as well as the workload and work project with equal number or steady growth in equal time. Equilibrium is not just the number, but also includes a full range of balanced type, hours of work, configure load. Only by achieving these conditions may result in high benefits with low-cost. Problems and significance of equilibrium production in complex manufacturing process

\section{EQUILIBRIUM PROBLEMS AND THE SIGNIFICANCE OF THE PRODUCTION OF COMPLEX MANUFACTURING PROCESS}

\section{A. Features of complex manufacturing}

There all several classification method of the manufacturing generally: classify by industry which is also product distinction, roughly machinery, electronics, automotive, food, chemical and pharmaceutical etc.; classify by production drive, roughly MTS (Make to Stock, for inventory production), MTO (Make to Order, for production orders), ATO (Assemble to Order, orderoriented assembly), ETO (Engineering to Order, according to the order structure ) and DTO (Design to Order, according to the order design). If follows the production volume distinction, there is a single product for small batch production, a large number of repeat production. If follows the production patterns distinction, there are discrete production, continuous production, but in addition to these common manufacturing categories, there is a classification which can not be ignored, and that is the complexity of the manufacturing enterprise, or complex manufacturing. How to determine if a business is a complex manufacturing? From our long-term experience, several characteristics are roughly summed up:

1) complexity of portfolio,

2) complexity of sales quotes complexity

3) complexity of plan layout complexity,

4) complexity of supply management

5) complexity of production coordination,

6) complexity of tooling equipment,

7) complexity of sales delivery,

8) complexity of after-service,

9) complexity of cost control,

10) complexity of knowledge specification. These characteristics are different aspects to measure whether a manufacturer is complex enough. Generally, these features are not isolated. 


\section{B. Problems in complex manufacturing process}

1) Basic information is growing rapidly, so that it is very difficult to fully regulate and manage

In complex manufacturing, the product can be configured in higher degree. As the continuous emergence of new product configuration requires continual emergence of new items, some of these items are disposable and is no longer used after one time, some is to have version control, and it can be used before the advent of the new version, but after the new version appeared, it will be no longer used.

2) Difficulties in production plan scheduling and organization

If the product is quite complex, so it is necessary to adopt a multi-level, multi-mode program management. .

3) Not easy to reduce inventory and cut costs

In the production processes of complex manufacturing, in order to meet the match of final product and the balance of production process, production steps of parts must be in strict accordance with the production plan. That is to do the things necessary in the necessary time to complete the necessary quantity.

4) Long production cycle, difficult to integrate the information

Because of huge enterprise scale, complex product structure, long production cycle, the various information islands are difficult to integrate into a standard integrated information sharing system. In complex manufacturing, mostly sales track sales with EXCEL; and the design department uses CAD software for planning; warehousing department uses inventory management software; financial accounting department uses financial software. The situation is very common. Thus, the information of each department is limited, isolated. The information does not form a closed loop, or entirety and is unable to be shared. And to integrate information islands, facilitate information sharing norms and, the difficulty lies in the following aspects:

The integrity of the system is not very good. Complex manufacturing itself also belongs to the manufacturing which has a full range of marketing, planning, supply, production, finance and other necessities, a lack of which is not complete. So the system used to integrate information silos must fully cover the entire enterprise business. It must be good integrity and can provide production, supply, marketing, financial integration solutions.

The system must be very tolerant. The features of complex manufacturing are very strong. It has very unique management requirements in articles version tracking, aspect breakpoint control, P-BOM, changes in technology, multi-level and multi-mode program, a variety of production methods, complex delivery process, etc. Therefore it requires solutions and applications which have a strong inclusive method to cover these management needs.

Another feature of the complex manufacturing is to require fast and flexible manufacturing. Sales quote requests quick response; the order changes also require rapid response. In addition, because the basic data amount is very large, the system applications also require flexible and simple operation, such as materials files- building, orders issued and approved. And a series of operations should be easy, simple and flexible to be modified.

\section{Significance of equilibrium production}

1) Get much closer to the real needs of customers and increase productivity

Due to the uncertainty of customer demand, every customer may have different requirements of product performance, appearance and delivery. If take certain different management in the production plan, then can be closer to the customer and market demand. Equilibrium production manufactures with mix production lines and can create diverse small batch production systems. Whatever the kind or quantity of the products, it is able to meet the real needs of customers which may increase production efficiency and enhance the competitiveness of enterprises.

2) Optimize distribution system of materials and components

After the implementation of equilibrium production, in order to meet on-time delivery, corresponding distribution system should be in accordance with the method of balance. Because the number of production under equilibrium conditions of production is generally very small, the use of small quantities of material distribution logistics model can not only realize the time of the request, but also reduces the cost of logistics and logistics risks.

\section{3) Operator becomes more skilled}

In mass production, only after finished one kind of products, then other products can be produced with a very long interval time, and operators may forget the practices of a product, resulting in the beginning of each replacement products are always of low efficiency, poor quality. However, according to the method of increasing frequency, reducing batch, the operator will constantly repeat daily production of different products, and become more and more skilled for a variety of products, even remember the operation method of each product deep in heart.

\section{4) Shorten the manufacturing cycle time}

Equilibrium production can increase the reaction speed to the market, provide an appropriate number of products requested by customer on time, and improve the company's image.

5) Little stocks or no inventory

By reducing inventory and prevent additional expenditure, the purposes of reducing costs and obtaining maximum profit. Because no inventory means additional costs, more profit can be made.

And if the production is not balanced, for example, loose at the beginning of a month tight at the end of a month or too tight or too loose from time to time, will result in idle staffing in loose time and overtime work to complete production tasks in tight time, which may cause poor quality easily and while workers are tired, it may result in security accidents, and machinery and equipment are not properly maintained with continuous work, causing excessive wear and tear, which easily cause equipment failure. Only by achieving equilibrium production and establishing normal production order, 
production capacity can be fully utilized to ensure a stable product quality. Defective rate will be reduced.

\section{Further improvements}

\section{1) Establish resource optimization control chain}

Production managers can use resource optimization control chain to balance the utilization of a variety of resources in production management and also to have dynamic coordination and control of the production. Resource optimization control chain is able to balance producing materials, energy and power, human resources, production efficiency, to solve a variety of needs of production. As equilibrium production is the ultimate goal of production plan, it can make use of resource optimization control chain to clarify the resources, to integrate the resources and control the project, and finally achieve the entire production balance.

The contents of resource optimization control chain are as follows:

The comprehensive integration and utilization of resources may balance the resources which can be shared the resource control chain network;

The resource can be managed and controlled better, formatting the control chain model to optimize the use of resources under control;

The establishment of production management network model enables all levels of management. It can receive and process information in the resource control chain;

Customers' targets and production can be achieved by network control. The achievements of resource optimization control chain network are as follows.

a) Build network of raw material and accessories

b) Build network of production process data

c) Build network of produce measurement system

d) The production management can achieve rapid resources balance and flow through the above resource optimization control chain.

e) The production network achieves the purpose of equilibrium production.

The establishment of resource optimization control chain system can best integrate resources, so that all network resources are able to reflect information to the management of all levels to have decision-making; the original production plan is relatively independent mode which is optimized to improve the response of the production management.

2) Achieve effective control of the production process

The main task of the production process is to prevent and stop target deviation and plan-off during production process through a variety of effective coordination measures and regulatory methods, and to ensure the intended target can be completed successfully. In the case without considering human factors, manufacturing process control mainly includes production schedule control, WIP control, cost control and quality control in production process.

can make work and staff to achieve equilibrium in line and ensure a balanced completion of the task.
Production schedule control: Production schedule control is one of the central tasks of production process control. Production schedule control is throughout the entire production from the beginning of work until the end of the production process. According to the balance of production, it not only require companies to complete the task on time, but also require companies to average each stage of production and each product, completing tasks daily, each ten days, monthly. The production schedule control aims to ensure the production process can be in continuous, rhythmic manner.

WIP control: WIP (Work In Process) refers to items that raw materials, purchased parts are input to production but have not passed the test or finished storage procedures, and items exist in all aspects of the production process parts. In order to make all aspects of the production process, each stage and each process can be carried out in accordance with plan rhythmically; WIP should be under the reasonable control. Control of the production process in the product make the logistics balance while stocks at the same time meet the production rhythm with minimum amount. This is for the healthy development of production.

Quality and Cost Control : To ensure that the production process of a system is in accordance with the standard quality requirements, it is necessary to test some products or even all of the products.

Production process control can eventually achieve the production process to maintain continuity, parallelism, proportionality, rhythm and adaptability

\section{a) The continuity of the production process}

The so-called continuous production process means the processed object once input to the production process, then go through each process and each processing stage continuously, or be processed or be tested, or transported. Waiting for unnecessary processing or treatment is not happening frequently.

\section{b) The parallelism of the production process}

Parallel production process refers to the process applies parallel operations during the various stages of the production process,

\section{c) The proportionality of the production process}

The proportionality of the production process mainly refers to the process between the different stages of the production process. Among production steps, the production capacity configuration and manufacturing requirements network should be in proportion, and it requires the production capacity of the production processes to maintain a reasonable proportion in order to ensure the production process is coordinated. That would ensure the full use of equipment, production area, labor and capital, and also to ensure the continuity of production.

\section{d) Rhythm of the production process}

Rhythm of the production process refers to the production should be completed as planned rhythmically from batch feeding to the finish of production, and to ensure equal time intervals, such as monthly, every ten days. The number of products produced per day should be approximately equal or in a steady increase which

e) The adaptability of the production process 
The adaptability of the production process, also known as flexibility, means company production process should have strong adaptability to the market. Rapid changes and diversification of market require the company production systems must face a changing environment, and adaptation of the production process is directly related to the implementation of the final production plan.

\section{CONCLUSION}

By observing and thinking in an equilibrium production implementation process, there are the following points needed to make further research and improvement, and these are as follows:

\section{A. Improve the transfer of logistic information.}

As companies mainly depends on paper documents to transmit information in the business process, and there is artificial transfer mode, resulting in documents information redundancy. The same information is repeated; scheduling, transportation, receipt and settlement operations are realized by EXCEL. Artificial operating is large, easy to make mistakes, which make business processing of low efficiency.

\section{B. Improve the evaluation index}

Because time is short and only for test point, besides the object embodiment is the same kind of product series, only focusing on equalization and production efficiency. It also needs observation for implementation for a subsequent series of products of different types. Longterm observation of other evaluation index is necessary with a more objective perspective to evaluate the results of equilibrium production.

\section{Establish quality control system}

Every process and every step in production systems will have a direct impact on manufacturing quality of products. Ensure every process to delivery 100 percent qualified components products to next processes.

\section{REFERENCES}

[1] Zhang Yunpeng, Performance management to promote equilibrium production in enterprises [J], 2013, China Aviation Institute of Management Sciences Branch Conference Proceedings 2013 (3) 45-67

[2] Zhou Wei, Dong Xuewu, Wang Wenhui, Heuristic discussion based on equilibrium production method [M], Group Technology \& Production Modern 2004042004 (5) 67-90

[3] Authored by Taiichi Ohno, translated by Xie Kejian, Li Yingqiu, Toyota Production System [M], Beijing: China Railway Publishing House, 2006.4

[4] Jay S, Young JS, Rechard A. Resource Modeling for the Integration of the Manufacturing Enterprise [J]. Journal of Manufacturing System, 2001, 19(6) 4072425.

[5] K. E. Steche, J. J. Solberg. Loading and Control Policies for Flexible Manufacturing Systems[J] .Int .J. Prod. Res... 1981(19) 481-190.

[6] ANWAR MF NAGI R. Integrated lot sizing and scheduling for just-in-time production of complex[M] J Sound and Vibration, 1993, 162(3) 387-401

[7] Dong Zhen, Methods of promoting equilibrium production Proceedings Institute of Management Sciences Branch of China Aviation Conference 2013 [J] .2013 (4) 23-60

[8] Wang Shilong, Cheng Changdong, Ren Hengbin, Improved production systems in many varieties and small batch manufacturing environment. Computer Integrated Manufacturing System [M]. 2009. 9, 15-9.

[9] Lu Xiaodong, Non-ferrous metal industry [M] Science and Technology Innovation Herald .2003 (3) 45-67

[10] Mai Jianmin, To achieve an equilibrium production to reduce energy use overtime [M]. Guangxi saving 2008 (2) 22-56

[11] Ye Shunyu, Li Qiulin, Achieve equilibrium production by resources optimizing control chain $[\mathrm{J}]$ Science and Technology Innovation Herald 2013 (6) 45-67

[12] Chen Jianfeng, Exploration of face-lifting equilibrium production lines [M] Private Technology 2009 (11) 33-35

[13] Geng Hao, Song Shudong, Xu Tongxun, Wang Yuehu, Strengthening production scheduling management achieving a balanced and stable production [M] Shandong Metallurgical 2007 (2) 89-96

[14] Wang Ge, An important part of modern production management - equilibrium production [M] Construction Machinery 2008 (3) $91-97$

[15 ] Hou Tiefeng, Sun Xiangyue, Modern business [M] 2007 (17) 45-67 